\title{
Priorities and the Place of Mental Health Services in Times of Financial Restraint
}

\author{
David TownSEND, Director of Social Services for the London Borough of Haringey
}

In these remarks I want to concentrate on services for mentally ill people, though many of my comments are relevant to the other two parts of that unhappy triumvirate of neglected services, mental handicap and old age. Though finances appear even more 'restrained' now, with the latest expenditure White Paper projecting a real drop of 2 per cent in personal social services spending between 1985 and 1988 , we should avoid an excess of political emotion over reason. There has been progress over the last ten years in promoting mental health. What the figures I will quote show, however, is how painfully slow and erratic these developments have been.

Over the past decade expenditure (exclusive of that spent by housing associations, housing departments, etc.) on mental illness services within total personal social services expenditure has been as follows at $1981-82$ prices: $1975-76, f 11.4$ millions on residential provision of a budget total of $£ 1,852.4$ millions (there was in that year no joint finance, it had not been invented) growing to $£ 17.1$ millions in $1980-81$ of a total $£ 2,126$ millions, but falling back to $£ 16.7$ millions of $£ 2,098$ millions in 1981-82. Day care for mental illness services has had an equally agonized growth-in 1975-76, f6.7 millions to $\mathbf{2 1 0 . 9}$ millions in 1981-82.

The cash figures take on real meaning when the number of places they pay for are measured. In the four years 1979-82, 1,000 extra residential places in statutory and voluntary hostels were provided, a rate of only 250 per annum. Contrast that with the decline of daily occupied mental illness beds: 9,000 between 1976 and 1979. Where did all those former users go? Death accounted for some, but hidden neglect, I suspect, for many more.

What has undoubtedly been of considerable assistance in concentrating attention on services for mentally ill people (and also for mental handicap and elderly people's services) has been joint finance. Of course, every silver lining has a cloud, and in the present financial framework set by the government, joint finance is becoming a penalty weighted burden to some, if not all, local authorities. Joint finance was a small initiative introduced during a previously stringent financial regime. It represented $£ 2.3 \mathrm{~m}$ out of a total of $\$ 1,901 \mathrm{~m}$ in its first year, 1976-77. By 1981-82 it had grown to $£ 49.2 \mathrm{~m}$ of $£ 2,098 \mathrm{~m}$.

Three things need to be said about the joint finance initiative. First, that throughout its progress roughly one-third of the total joint finance has gone on each of the three priority services. Second, that local authorities have continually argued that joint finance should be a permanent transfer of cash from health to the personal Social Services. The opportunity which the closure of major psychiatric hospitals now presents to transfer cash direct to the local authorities, with joint health and local authority agreement, shows that the local authorities' view of joint finance was and is a wholly reasonable and consistent one. Third, the financial framework of rate penalties and probably 'rate capping' is not conducive to the continuing small success story of joint finance. To a minor extent, the government has acknowledged this. As from this year, the annual proportion of joint finance of which the NHS is still paying part is exempt from rate penalties. But the cumulative total is not exempt, so that in 1984-85 my own council has exemption on about $\{100,000$; but in 1986-87 will have a cumulative total of over $₫ 1 \mathrm{~m}$, none of which is exempt. One-third of that expenditure is on services for mentally ill people. Unfortunately for them there are more ways than one to skin joint finance.

'Rate capping', as a blunt instrument, is in a class of its own and it may have the crudest effect on the way mental health is regarded. My own department is said to be $16.5 \mathrm{~m}$ per year 'over approved levels', based on the Department of the Environment's Grant Related Expenditure Assessment figures. For 'rate capping' purposes by the Secretary of State such an expenditure assessment is taken into account. There could be a heavy price to pay, and not by the local authority alone. Some of my department's alleged 'overspending'-and we have not even reached the now abandoned DHSS guidelines for mental health, handicap or elderly people's services-is in the form of grant aid to voluntary organizations which provide alternative or complementary mental health services. My authority makes a substantial annual contribution to the Psychiatric Rehabilitation Association and without it the organization is in difficulties; without the organization's services Haringey's provision for mentally ill people is diminished. The same applies to 'Mind' in Haringey, which organization is actively involved with us in planning and providing accommodation for people discharged under the regional closure of hospitals plan.

What we see in all this from a local government point of view is confusion by central government departments. By all means take joint finance, urges the DHSS; prepare to be mugged, warns the DoE. If central government is serious about priorities for mental illness, then it must put its own house in order. Consistency and flexibility is what local authorities and, if I may presume to speak for my colleagues, District Health Authorities, require. Just one last example of inconsistency before I embrace mild optimism. Last year, immediately after the General Election, by order of the Chancellor, a recurring $\{10,000$ per annum was removed from Haringey District Health Authority and Haringey Council's joint finance budget. It helped to put back two small schemes we would have introduced for mentally ill and mentally handicapped people later this year.

The sad thing is that there are now opportunities for the emergence of a renewed and real sense of priority for mental health services. The 1983 Mental Health Act and Mental Health 
Commission can raise the quality of what we have and what we may be able to introduce; the closure of big old psychiatric hospitals releases cash to build alternative services; the emergence of 'Care in the Community' programmes may in time become as important as joint finance in concentrating resources (and minds) on how to provide effective services. But all of that is in danger of being hide-bound, if not still-born, not by attempts to obtain 'value for money'-all governments should encourage that - but by a narrow ideological view of a 'proper' level of public expenditure, regardless of value.

If making mental health services a priority can gain ground, then there are a range of professional interests and more important traditional attitudes which will have to change. Is it not extraordinary that psychiatrists should be paid extra to make domiciliary visits to people when 95 per cent of those suffering from mental illness are not in psychiatric hospitals? To get more psychiatrists to view their base of operation as 'the community' rather than hospitals will take time and accounts for the opposition of some to the proposed closure programme. Nevertheless, without the willing and active support of the majority of psychiatrists, community mental health services will not succeed. Italy shows just such a regional patchwork of keen initiatives and sluggish traditionalism. It is encouraging that housing associations are now much more active and enthusiastic about making provision for mentally ill people. The DoE survey of 1983 showed 622 housing schemes for mentally ill people, and 31 for both mentally handicapped and mentally ill people. The number of mentally ill people so accommodated was 3,300 , and although the majority were in local authority housing, nearly one-third were in housing associations properties.

A greater part in community provision by housing departments and housing associations must be a tradition of the future. Social services departments and their staffs will have to alter attitudes too; or at least accept that a community mental health service cannot be, as it often is at present, a 9-5 pm, 35-hour, five days a week job. Residential staff and some day care staff know this already. All such changes will mean extra costs.

And where is the extra money to come from? It is not only a question of more money, though a reduction of PSS spending will make the whole prospect of new mental health services impossible. There are, as every government knows, inexorable pressures, well documented, from a growing number of very frail, confused elderly people for more health and personal social services. They present a pressing priority; in circumstances where expenditure may decline, their claims will not be ignored. Mental health would be one of the losers. So some relaxation of cash limits is essential. Given the public spending stance of the present government, that relaxation could be quite specific, without 'printing money' or upsetting the economics of the grocery shop. No penalties on schemes for the priority groups which have been joint financed is one small assistance. Better still would be a permanent transfer of joint finance cash from the NHS; the new programme of NHS money from closures may well be bigger than joint finance and establishes a precedent. The exemption from rate penalties of urban aid and inner city partnership cash (which I regret to say my own authority, though well qualified, does not receive), where that is for specific priority service grants, could be made. The use of more specific grant aid for certain services, for example, section 11 from the Home Office, for mental health programmes amongst people of the ethnic minorities and the enlargement of the cash available to housing associations for mental health schemes are both small ways, but of significance in developing some aspects of mental health services.

Above all local and district health authorities require an assured financial framework in which to plan ahead. The agreements about funding which they reach must be guaranteed. It cannot be said that they have experienced the necessary stability in the last four years. So long as insecurity about future central government policies and attitudes continues, so long will mental health policies receive less priority than they deserve. So long too, to the bright hopes of 1983 .

This paper was presented at a meeting of the All Parry Parliamentary Mental Health Group at the House of Commons in May 1984.

\section{European Working Group on Drug Policy Oriented Research}

An international workshop on drug policy oriented research was held for the first time in Rotterdam on 14 and 15 December 1983 organized by the Institute of Preventive and Social Psychiatry of the Erasmus University. At this meeting the participants decided to establish an European Working Group on Drug Policy Oriented Research (EWODOR). This working group will meet once a year; participation is by invitation only and will be limited to research workers.

At the initial meeting some of the topics discussed were the general economy of drugs; the illegal heroin market in The Netherlands; evaluation of the distribution of morphine in Amsterdam; treatment motivation of addicts; and evaluation of treatment in therapeutic communities. The Working Group intends to draw more attention to issues of research in this undervalued field and to stimulate national and international co-operation of researchers. The next meeting will be on 13 and 14 December 1984. Information: Wijnand Sengers, Erasmus University, PO Box 1738, 3000 Rotterdam, The Netherlands.

\section{Disabled Living Foundation}

The Disabled Living Foundation is moving from $346 \mathrm{Ken}$ sington High Street, London W14 8NS to new premises at 380/ 384 Harrow Road, London W9 $2 \mathrm{HU}$ in November/December 1984 (telephone number 01-289 6111). 